Table 1-Prevalence of antibody to $\mathrm{H}$ pylori and $\mathrm{C}$ pneumoniae in patients with acute myocardial infarction and controls. Figures are numbers (percentages)

\begin{tabular}{|c|c|c|c|c|}
\hline & \multicolumn{2}{|c|}{$\begin{array}{l}\text { Patients with acute myocardial } \\
\text { infarction }(n=37)\end{array}$} & \multicolumn{2}{|c|}{ Controls $(n=60)$} \\
\hline & $\begin{array}{c}C \text { pneumoniae } \\
\text { positive }\end{array}$ & $\begin{array}{c}C \text { pneumoniae } \\
\text { negative }\end{array}$ & $\begin{array}{c}C \text { pneumoniae } \\
\text { positive }\end{array}$ & $\begin{array}{c}C \text { pneumoniae } \\
\text { negative }\end{array}$ \\
\hline H pylori positive & $28(76)$ & $4(11)$ & $12(20)$ & $20(33)$ \\
\hline H pylori negative & $3(8)$ & $2(5)$ & $18(30)$ & $10(17)$ \\
\hline
\end{tabular}

bacteria, mediated by IgE, could be responsible for the enhanced production of interleukin 6 . The intense proinflammatory and procoagulant properties of this cytokine could account for most, if not for all, acute coronary syndromes. ${ }^{5}$

\section{ANTONIO ACETI}

Director

Institute of Infectious Diseases,

University of Sassari,

Sassari,

GIORGIO MAZZACURATI MARIA A AMENDOLEA Senior registrar ALFREDO PENNICA Assistant Biologist BARBARA ZECHINI Research fellow

Department of Infectious and Tropical Diseases,

La Sapienza University,

Rome,

Italy

MASSIMO TRAPPOLINI

Medical Department 2

1 Mendall MA, Patel P, Ballam L, Strachan D, Northfield TC. C reactive protein and its relation to cardiovascular risk reactive protein and its relation to cardiovascular risk
factors: a population based cross sectional study. BMY 1996;312:1061-5. (27 April.)

2 Patel P, Mendall MA, Carrington D, Strachan D, Leatham E, Molyneaux N, et al. Association of Helicobacter pylori and Chlamydia pneumoniae infections with coronary heart disease and cardiovascular risk factors. BMף 1995;311:711-4.

3 Aceti A, Celestino D, Caferro M, Casale V, Citarda F, Cont $\mathrm{EM}$, et al. Basophil-bound and serum Immunoglobulin $\mathrm{E}$ directed against Helicobacter pylori in patients with chronic gastritis. Gastroenterology 1991;101:131-7.

4 Emre U, Sokolovskaya N, Roblin PM, Schachter J, Hammerschlag MR. Detection of anti-Chlamydia pneumoniae IgE in children with reactive airway disease $f$ Infect $D$ is 1995;172:265-7.

5 Maseri A, Biasucci LM, Liuzzo G. Inflammation in ischaemic heart disease. $B M F$ 1996;312:1049-50. (27 April.)

\section{Drug use in prison}

Methadone maintenance in prison needs to be evaluated

EDITOR,-Kate Dolan and colleagues claim, on the basis of inadequate data, that methadone maintenance reduces injecting in prison. ${ }^{1}$ This claim is based on recall of the number of injections in prison per week by a subgroup (number not stated) of ex-prisoners who-inside prison-both had received a maximum methadone dose exceeding $60 \mathrm{mg}$ and had not defaulted from the programme.

The efficacy of methadone maintenance in prison should be evaluated prospectively in randomised controlled trials analysed on an intention to treat basis. ${ }^{2}$ For modest targetssuch as a reduction from $70 \%$ recidivism to $60 \%$ in the year after discharge from the index sentence and a reduction of $25 \%$ in the median number of days' incarceration for recidivists (down from 88 to 66 days) - to be identifiable in tests of significance, the consent of some 800 inmates who inject drugs would be required.

Any trial of methadone maintenance in prison should take into account the fact that $35 \%$ of prison terms for injecting drug users may last for less than 10 days and only $20 \%$ for more than 100 days (unpublished findings based on a study of 300 injecting drug users with a median of four (range one to 28) terms in Saughton prison, Edinburgh between 1983 and 1994). If the data from Edinburgh are typical, methadone maintenance in prison is mostly of short duration. The efficacy of this is unclear because most studies in the outside community have been of longer programmes (and have been non-randomised and inadequate in size) and have excluded defaulters from analysis. ${ }^{3}$

SHEILA M GORE SHAUN SEAMAN

MRC Biostatistics Unit,

Institute of Public Health

Cambridge CB2 2SR

1 Dolan K, Hall W, Wodak A. Methadone maintenance reduces injecting in prison. BMF 1996;312:1162. (4 May.)

2 Smith T. Evidence based politics. BMF 1996;312:127. (13 January.)

3 Ward J, Mattick R, Hall W. Key issues in methadone maintenance treatment. Sydney: University of New South Wales Press, 1992.

\section{Access to sterile injecting equipment is important}

EdTor,-As Kate Dolan and colleagues comment, substantial drug misuse continues even in prison. ${ }^{1}$ As many as $70 \%$ of all prisoners will probably use a controlled drug. ${ }^{2}$ Research at Maryland Centre in Liverpool shows that 83 of 87 injecting drug users who were interviewed had been in prison and that 71 had used drugs there. Of these 71, 21 had injected, of whom six $(29 \%)$ had used non-sterile injecting equipment. This compares with a sharing rate of $14 \%$ recorded at the syringe exchange.

Despite recommendations from the health care directorate for England and Wales ${ }^{3}$ the prison service has been reluctant to introduce methadone maintenance treatment and have relied on often inappropriate drug treatments for symptomatic relief. Methadone should be considered as it may have a valuable role in reducing the contribution of opiate withdrawal to suicide rates in prison. Although prescribing of methadone might have an impact on opiate inject stimulants, for whom the need for access to sterile injecting equipment, as in the community, remains a crucial factor.

Along with the introduction of mandatory drug testing ${ }^{4}$ there has been a growth in the use of a range of treatment modalities, including drug education programmes, individual counselling, and drug awareness courses. We advise caution over the general acceptance of such services in prisons. While we recognise the importance and value of counselling and education, awareness in itself is not sufficient to reduce the risk of communicable disease.

Current political rhetoric surrounding crime, law, and order and the home secretary's insistence that prison reduces crime may increasingly lead to a criminal justice system that regards a prison sentence as offering a credible drug treatment service. There is likely to be an increasing emphasis on imprisonment as the best option. Such responses further criminalise what for many people is essentially a sociomedical problem.

A report by the North West Regional Health Authority stated that services that intervened early and diverted drug users from prison would reduce the costs to the community in terms of crime and public health. ${ }^{5}$ Prison can recruit people into drug use, while the environment and lack of access to users, it would be of no benefit to users who sterile injecting equipment are not conducive to reducing drug related harm. When users continue to inject in prison, rates of sharing of equipment are higher than those in the community.

CLIVE L MORRISON

Senior clinical medical officer

ALAN MCGEE

Maryland Centre,

Liverpool L1 9DE

1 Dolan K, Hall W, Wodak A. Methadone maintenance reduces injecting in prison $B M F$ 1996;312:1162. (4 May.)

2 Hewitt A. Drug testing in prisons. Druglink 1996;11(3):16-8.

2 Hewitt A. Drug testing in prisons. Druglink 1996;11(3):16-8. ment. London: PS, 1995.

4 Prison Service. Clinical services for substance misusers. Health Care Standard 1995; No 8.

5 Health Care Development Unit. The criminal justice system and the care of drug users. Manchester: North West Regional Health Authority, 1996.

\section{National crash call number is needed}

EDITOR,-Cardiac arrest is one of the most dramatic events that occur on hospital wards. The successful outcome of such an event may be influenced by prompt treatment. To this end, all staff on hospital wards should be trained in basic life support. They should also be familiar with the process of summoning the hospital's cardiac arrest team to proceed to advanced life support. This is normally done by dialling the crash call number either through the hospital's switchboard or direct.

Table 1-Crash call numbers used by 40 hospitals

Crash call number

No of hospitals

2222

333

3333

$-666$

Other*

8

4
11

"Nine other numbers were used.

We have noticed that the different hospitals where we have worked have used different crash call numbers. To establish the diversity of such numbers in different hospitals and whether they are in any way predictable we performed telephone survey, requesting information from the switchboard operators of $\mathbf{4 2}$ acute hospitals in the two North Thames regions (North East Thames and North West Thames). Two hospitals refused to disclose the information. Fourteen dialling numbers were used in the two regions (table 1), 2222 and 333 being the most common. There was no geographical basis for such differences, nor was there any difference in the degree of diversity within the two regions. Surprisingly, some hospitals in the same NHS trust but at different sites used different numbers. Three hospital operators could not readily remember the crash call number in their own hospital.

With the regular movement of medical staff in training posts between hospitals and the frequent temporary employment of locum doctors and agency nurses, the use of different crash call numbers may impair the speed with which help can be summoned and may adversely affect the outcome of cardiac arrests. We suggest that all hospitals should adopt a national crash call number analogous to the 999 number used by the public to call the emergency services.

Senior registrar Registrar

FATHI S AL-JEHAN

Department of Medicine, Senior house officer

Central Middlesex Hospital,

London NW10 7NS 